
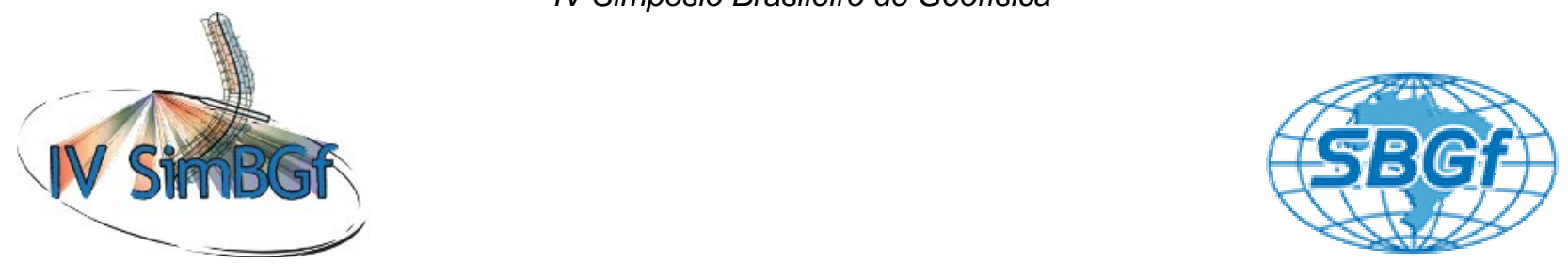

\title{
APLICAÇÃO DO RADAR DE PENETRAÇÃO NO SOLO (GPR) NA DEFINIÇÃO DA ESTRUTURA INTERNA DE DUNAS DA REGIÃO METROPOLITANA DE FORTALEZA
} CASTELO BRANCO, Raimundo Mariano Gomes (1); PEDROSA JúNIOR, Nilo Costa (1); MAIA, Luis Parente (1,2); MARTINS, Jackson Alves (1); VIEIRA, Nilton César (1); AMORIM, Ailton Nascimento (1); BRAGA, Luiz Ricardo Cunha (1). (1) Laboratório de Geofísica - Universidade Federal do Ceará; (2) Instituto de Ciências do Mar - Universidade Federal do Ceará.

Copyright 2010, SBGf - Sociedade Brasileira de Geofísica

Este texto foi preparado para a apresentação no IV Simpósio Brasileiro de Geofísica, Brasília, 14 a 17 de novembro de 2010. Seu conteúdo foi revisado pelo Comitê Técnico do IV SimBGf. mas não necessariamente representa a opinião da SBGf ou de seus associados. É proibida a reprodução total ou parcial deste material para propósitos comerciais sem prévia autorização da SBGt.

\section{Resumo}

A compreensão da dinâmica costeira é o ponto inicial para se entender a evolução desses ambientes, determinando sua morfologia e seqüência sedimentar. A configuração que uma região costeira assume nada mais é do que o resultado do somatório de forças exercidas sobre ela. Portanto, através da topografia de uma duna se tem condições de avaliar a que tipo de dinâmica ela está sendo submetida. Essa pesquisa inicial objetiva caracterizar a estrutura das dunas costeiras da região metropolitana de Fortaleza por meio de Radar de Penetração no Solo (GPR), numa tentativa de compreender a sua arquitetura deposicional, tendo por fim o reconhecimento das heterogeneidades faciológicas e o refinamento do modelo deposicional existente, com amplas aplicações na modelagem geológica, inclusive, de campos produtores de óleo e gás. A pesquisa de água subterrânea no meio sedimentar pode ser igualmente, evocada.

\section{Introdução e Caracterização da Área de Investigação}

Segundo Araújo et.al. (2005) o uso intensivo do GPR em investigações sedimentológicas é bastante recente, tendo início somente na década passada, mas que vem apresentando forte aceitação entre os estudiosos desta área devido à velocidade de aquisição de informação das estruturas internas presentes em subsuperfície de depósitos sedimentares não consolidados. De certo modo há uma velocidade razoável no processamento e interpretações dos dados adquiridos.

As dunas e paleodunas quaternárias ocupam uma pequena área bordejando a orla costeira da região metropolitana de Fortaleza, com largura média de 2,5 km, adentrando um pouco mais ao continente nos setores central - município de Fortaleza, e leste - município de Aquiraz. Formam campos morfologicamente homogêneos, recortados ocasionalmente pela rede de drenagem e possibilitando a existência de lagoas interdunares (Figura 1).
Este sistema Dunas/Paleodunas da RMF foi mapeado hidrogeologicamente pela primeira vez por Bianchi et. al. (1984), que delimitaram 9 campos com áreas oscilando de 50 a 3.227 ha e altitudes variando de 10 a 60 metros. É composto por areias pouco consolidadas e extremamente homogêneas, finas a médias, com diâmetro efetivo predominando entre 0,15 e $0,25 \mathrm{~mm}$ e espessuras entre 10 e 25 metros. Ocasionalmente ocorrem intercalações de níveis síltico-argilosos a argilosos, oriundos da própria variação da energia de deposição dos clásticos, e a presença de intercalações de argilas orgânicas, de tonalidades escuras, a exemplo do que existe em Abreulândia e Cocó.

Em geral, repousam sobre os sedimentos Barreiras ou sobre manchas aluvionares. Indiscutivelmente constitui o melhor potencial hidrogeológico da região estudada, representando um aqüífero livre, com espessuras saturadas oscilando de poucos a até 10 metros e nível estático normalmente sub-aflorante nas áreas de descarga, atingindo, em média, 6,0 metros. As águas são captadas através de poços tubulares rasos, com profundidades inferiores a 20 metros e perfurados normalmente com 10". São revestidos com 6" ou 4", produzindo uma vazão média de $6,0 \mathrm{~m}^{3} / \mathrm{h}$ podendo alcançar, localmente, até $15 \mathrm{~m}^{3} /$ hora.

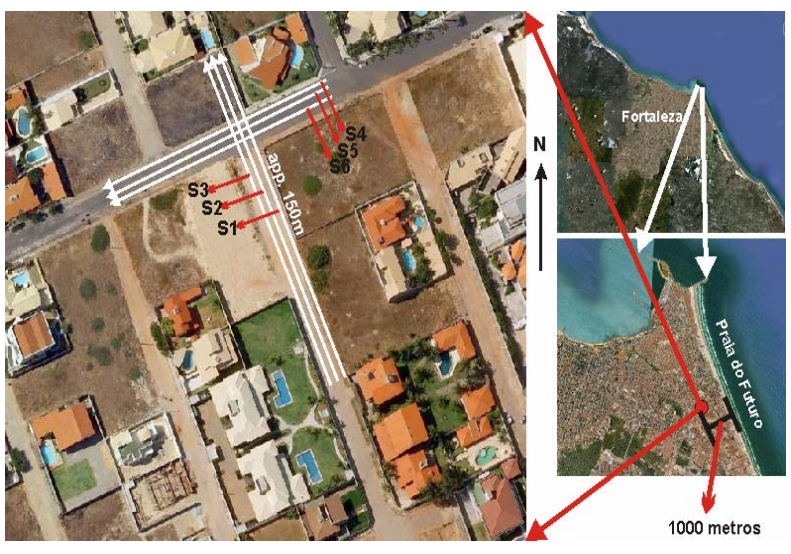

Figura 1 - Localização de 6 seções GPR adquiridas no Bairro Dunas na cidade de Fortaleza, NE do Brasil. 
Possui como característica básica uma dupla função hidrogeológica, refletida no funcionamento do sistema como aqüífero principal e aqüífero de transferência do potencial hídrico para unidades sotopostas, a exemplo do Barreiras.
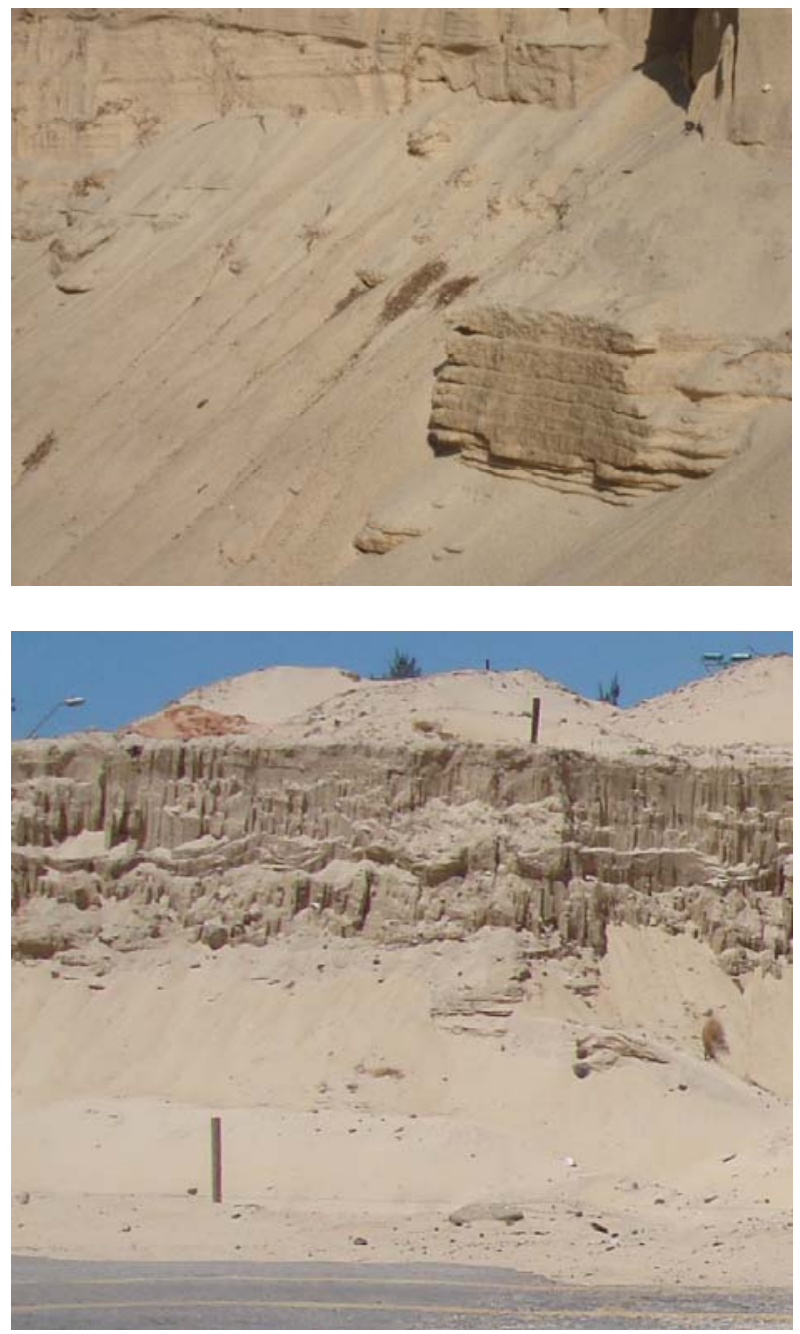

Figura 2 - Estruturas sedimentares planares e onduladas observadas em superfície na área de aquisição.

\section{Metodologia Geral e Técnicas}

A área indicada na figura 1 foi selecionada para aplicação do método GPR por se tratar de um importante sistema dunar, fortemente elevado e localizado em zona urbana costeira do município de Fortaleza, Ceará. Nesta pesquisa foi utilizado um sistema de Radar de Penetração no Solo (GPR) fabricado pela empresa GSSI americana modelo SIR 3000. A antena de freqüência centrada de $200 \mathrm{MHz}$ acoplada a um odômetro, ambos também da GSSI, foi utilizada nas aquisições aqui apresentadas. Duas outras antenas da Radarteam da
Suécia com freqüências de 70 e $40 \mathrm{MHz}$ foram também utilizadas. Nas figuras 3 e 4 se observam o sistema de aquisição apresentado um momento de coleta de dados em uma das seções da figura 1.

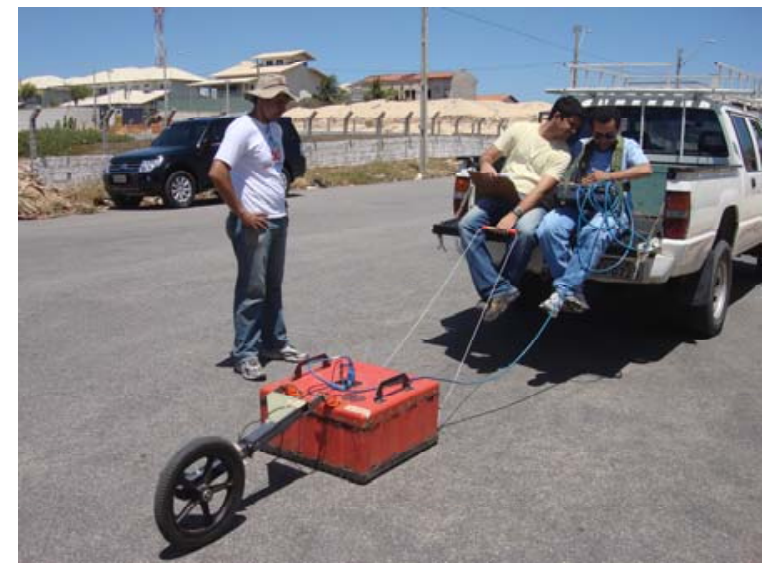

Figura 3 - Aquisição de dados GPR SIR 3000 com antena com freqüência centrada de $200 \mathrm{MHz}$ (seção 4).

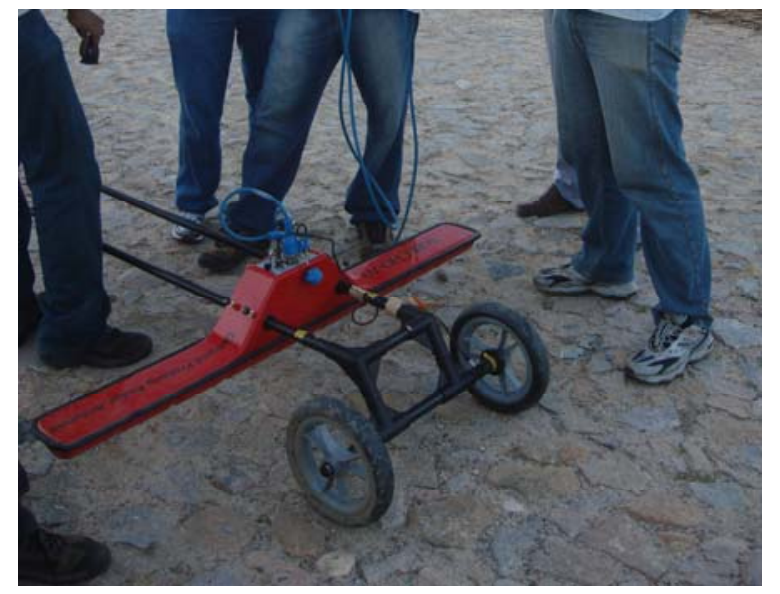

Figura 4 - Aquisição de dados GPR SIR $3000 \mathrm{com}$ antena Sub-echo com freqüência de $70 \mathrm{MHz}$ (seção 2).

Os parâmetros de aquisição iniciais para a antena de 200 $\mathrm{MHz}$ foram uma freqüência de $100 \mathrm{MHz}$, freqüência de amostragem de $12 \mathrm{KHz}$, amostragem de $512 \mathrm{em} 16$ bits, janela temporal de $100 \mathrm{~ns}$, taxa de transmissão de 15 $\mathrm{KHz}$, filtros passa baixa de $50 \mathrm{MHz}$ e filtro passa alta de $600 \mathrm{MHz}$ e um stacking de 0.

Os dados foram processados no software ReflexW, versão 5.0 (Sandmeier, 2009). A rotina de processamento consistiu em conversão de formato do arquivo, ajuste do tempo zero que é um ajuste feito em função da chegada da onda aérea, filtros temporal (dewow e passa-banda), ganho (decaimento de energia) que é um filtro visando compensar a perda de amplitude 
do sinal, migração no domínio do tempo (fk migration Stolt). Foi ainda realizada a remoção de background e conversão de tempo de propagação em profundidade utilizando a velocidade constante calculada pelo ajuste da velocidade em algumas hipérboles formadas pela reflexão da onda presentes no solo raso da área e correspondente a tubulações hidráulicas. A velocidade usada no processo de migração ( $f k$ Stolt) foi de $0,13 \mathrm{~m} / \mathrm{ns}$.
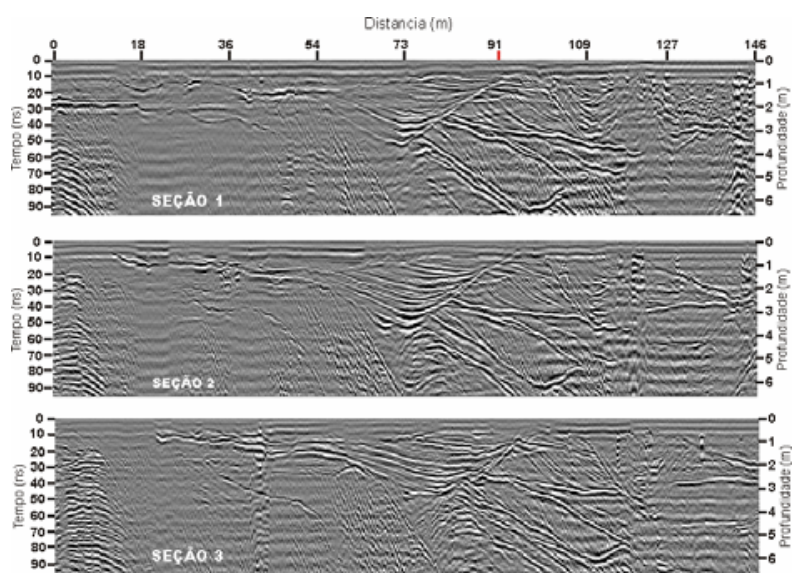

Figura 5 - Seções 1, 2 e 3 (conforme figura 1) processadas.
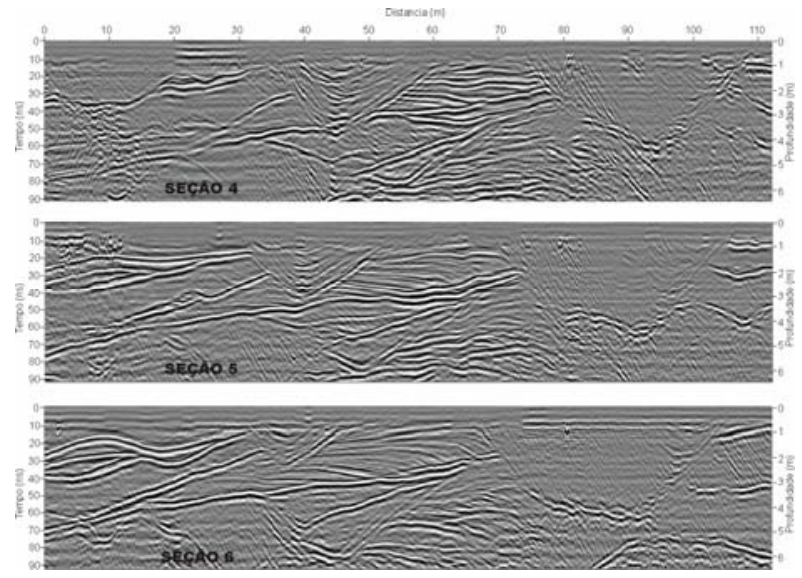

Figura 6 - Seções 4, 5 e 6 (conforme figura 1) processadas.

\section{Resultados e Discussões}

Em geral, foram identificados dois tipos principais de estratificações cruzadas, sendo definida como uma camada consistindo de lâminas internas inclinadas em relação ao plano principal de sedimentação. As estratificações cruzadas tabulares com os planos de definição entre as camadas paralelos ou semi-paralelos entre si e as estratificações cruzadas acanaladas com os planos de definição entre as camadas curvas e com aspecto acanalado.

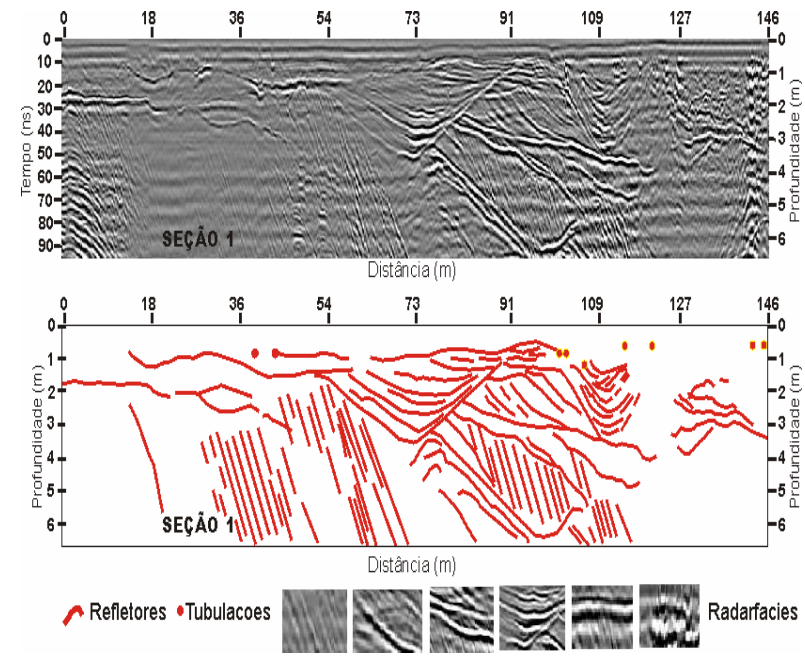

Figura 7 - Exemplo do processamento e da interpretação. para a seção 1. Essa figura foi suavemente deformada verticalmente para efeito de visualização.

Como se pode observar o início das seções (a exemplo da seção 1, figura 7) é marcado pela presença de planos inclinados com fortes ângulos de mergulho na direção de transporte, correspondendo às camadas frontais de sotavento das dunas, com transporte dominantemente em avalanches (Figura 5). Nas dunas atuais este ângulo corresponde ao ângulo de equilíbrio, sendo da ordem de $34^{\circ}$ na face de deslizamento.

Sobre estes planos frontais aparecem superfícies de segunda ordem limitando os sets, formados por estruturas em pequenos montículos e sistemas com estratificação cruzada acanalada e acanalada cuneiforme, típico da migração de pequenas formas de dunas. Este sistema de estruturas sedimentares cruzadas acanaladas e festonadas foram identificados anteriormente por Castro et.al. (2006) nos eolianitos da região costeira de Uruoca, litoral oeste do estado do Ceará.

No segundo grupo de seções (figura 6), se observa no início superfícies de segunda ordem sub-horizontais com ângulo de acamamento próximo a $3^{\circ}$ e que corresponde à face de barlavento das dunas. Sob estas superfícies aparecem planos frontais, indicando a direção do transporte. Em seguida, aparecem estruturas semelhantes ao primeiro grupo formado por estratificações cruzadas acanaladas com largura das bordas variando entre 25 e 40 metros, e profundidade dos canais da ordem de 4 metros. Na seção 4 , também é identificado na distancia de 80 metros a presença de uma hipérbole (Figura 6).

Por outro lado, a figura 8 ilustra uma perspectiva do cruzamento ortogonal das linhas 1 e 4 adquiridas com a antena de $200 \mathrm{MHz}$. Ai se nota a congruência perfeita da estrutura acanalada central das figuras 5 e 6 . Para 
melhor visualização deste tipo de informação somente uma aquisição 3D resultaria em melhor processamento.

Já na figura 9, se apresenta o resultado da mesma seção 1 , mas com a antena de freqüência de $40 \mathrm{MHz}$. Pode ser observado o importante ganho na profundidade de investigação para uma mesma velocidade de migração. Notar que as mesmas estruturas rasas aparecem, embora com menor resolução na porção rasa.

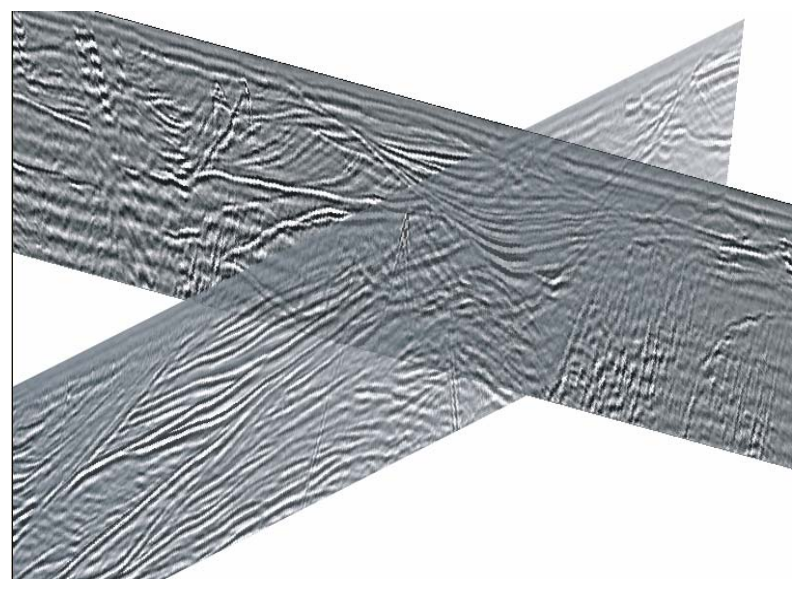

Figura 8 - Figura ilustrando em perspectiva o cruzamento ortogonal das linhas 1 e 4 . Essa figura foi suavemente deformada verticalmente para efeito de visualização.
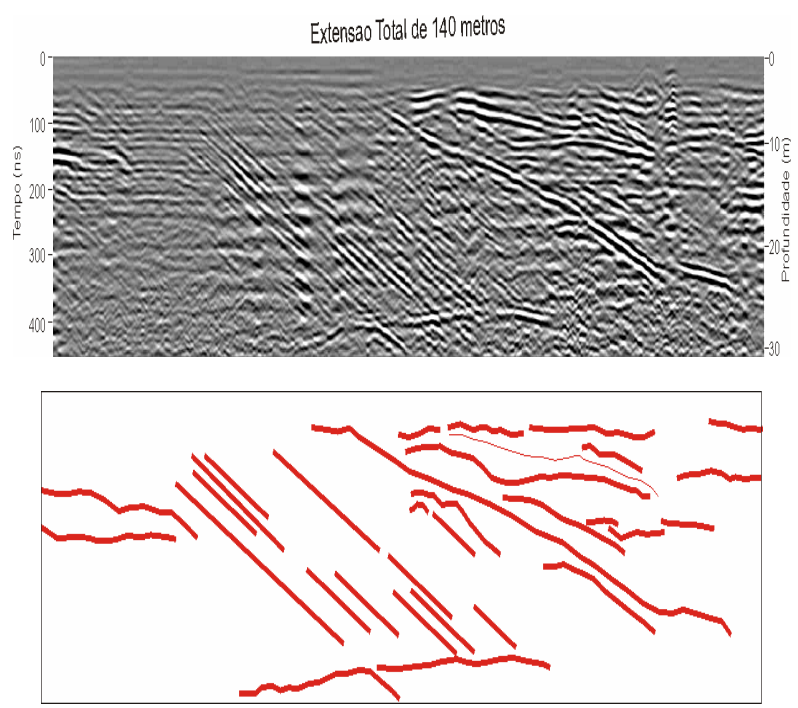

Figura 9 - Radargrama obtido após processamento para a antena Sub-echo de $40 \mathrm{MHz}$, correspondente a seção 1de $200 \mathrm{MHz}$ e sua respectiva interpretação inicial.

Observa-se que as estruturas sedimentares da duna atingem profundidades em torno dos 30 metros e há o aparecimento de um importante refletor mais ou menos horizontalizado que pode corresponder, muito provavelmente, ao nível estático do sistema aqüífero dunas em torno dos 25 metros de profundidade.

\section{Conclusões e Avanços da Pesquisa}

A excelente qualidade das imagens radar obtidas no levantamento com o GPR reforçam a importância que essa ferramenta geofísica possui para o entendimento da estratigrafia costeira bem como na definição da estrutura interna dos sistemas dunares. O método também demonstrou ser ágil durante o levantamento de campo, permitindo a obtenção de resultados em um espaço de tempo relativamente curto quando comparado a outras técnicas, além de ser valioso no estudo de regiões "desérticas" devido à boa penetração da onda eletromagnética em terrenos arenosos (alta resistividade), como é o caso dos depósitos sedimentares em questão.

Certamente, a qualidade das imagens obtidas nos radargramas se deve à escolha da freqüência ideal das antenas utilizadas no levantamento (velocidade de penetração da onda eletromagnética), e do processamento adequado para o padrão geológico local, bem como, o tipo e o arranjo dos sedimentos existentes.

Foi possível imagear o padrão das principais radarfácies bem com o contato e a terminação dos refletores sedimentares das dunas em suas porções rasas.

Exemplo da aplicação destas informações pode ser observado, por exemplo, no limite ocidental da Bacia do Recôncavo, a mais antiga bacia petrolífera do Brasil, onde existe uma crista de arenito que se prolonga por dezenas de quilômetros apresentando estratificações horizontais e cruzadas acanaladas observadas em afloramentos e que foram interpretadas respectivamente como interdunas e dunas. Estas rochas que ali afloram são os principais reservatórios de petróleo da bacia (Lanzarini, 1995).

Devido ao excelente imageamento das estruturas sedimentares aqui visualizadas se pretende dar continuidade as aquisições de dados GPR nesta área, inclusive com seções mais regionais desde o nível de praia dali afastado até esta área. Um imageamento com maior profundidade de investigação com as antenas de menor freqüência como aquelas de 70 e $40 \mathrm{MHz}$, serão continuadas. Almeja-se, também, uma configuração 3D em algumas destas estruturas dunares.

\section{Agradecimentos}

Este trabalho, em um dos dias de aquisição de dados, contou com a presença de alunos da disciplina Geofísica da UFC do semestre 2010-2. Contou ainda com a colaboração de José Albuquerque Sobrinho, dos alunos e bolsistas Lívio Alexandre e Fabiano Mota, Caio Jucá e a Karen Leopoldino. 


\section{Referencias Bibliográficas}

ARAUJO, V.D., PEREZ, Y.A.R.,MENEZES, L., SOUZA, A.M., FREIRE, R.C., MOURA, M.V.M., GAUW, D.S., SANTOS, D.A.S., PELOSI, A.P.M.R., CÓRDOBA, V.C. \& LIMA FILHO, F.P. -2004 - Imageamento tridimensional de um Blowout em Nísia Floresta, Litoral Oriental do Rio Grande do Norte. 3 Congresso Brasileiro de Petróleo e Gas.

BIANCHI, L; PADILHA, M.W.M; TEIXEIRA, J.E.M. - 1994 - Recursos de Água Subterrânea na RMF. Fatores Condicionantes. In: Plano de Aproveitamento dos Recursos Hídricos na RMF. - Fase I. Fortaleza. SEPLAN - AUMEF, v. 1,139 p.

CASTRO,D.L.; CARVALHO,A.M.; BRANCO,R.M.G.C. 2006. Uso do GPR no estudo da estruturação interna de depósitos de eolianitos na região costeira de Uruoca-CE. Fortaleza. Revista de Geologia, 19 (1): 126-134.

LANZARINI, W.L. 1995. Modelos e simulações de fácies e seqüências sedimentares fluviais e eólicas de reservatórios petrolíferos. São Paulo, IGc/USP, 205p.

SANDMEIER, K.J., 2009. REFLEX, Sandmeier Software, Alemanha. 